\title{
A Genetic non-insulin dependent diabetic mice, KK-Ay mice, is elevated alpha-glucosyldisaccharide digestive/absorptive capacity in small intestine
}

\author{
Toshiniro Miura', Eriko Ishihara ${ }^{1}$, Hitoshi Ishida ${ }^{2}$, Yutaka Seino ${ }^{3}$, and Keitchiro Tanigawa \\ ${ }^{1}$ Suzuka University of Medical Science and Technology, 1001-1 Kishioka, Suzuka, Mie. 510-0293, Japan \\ ${ }^{2}$ Third Department of Internal Medicine, Kyorin University School of Medicine, 6-20-2 Shinkawa, Mitaka, Tokyo 181-8611, \\ Japan \\ ${ }^{3}$ Department of Metabolism and Clinical Nutrition, Kyoto University Faculty of Medicine, 54 Shogoin-Kawahara-cho, Sakyo-ku, \\ Kyoto 606-0123, Japan
}

\begin{abstract}
The alpha-glucosyldisaccharide digestive/absorptive capacity was studied in normal and KK-Ay mice, an animal model of non-insulin dependent diabetes mellitus (NIDDM). KK-Ay mice with hyperglycemia exhibited significantly increased maltose and sucrose digestive/ absorptive capacity in small intestine $(P<0.05)$ when compared with that of normal mice. However, lactose digestive/absorptive capacity was not changed between them.
\end{abstract}

Increased glucose uptake in small intestine has been known as one of the major pathogenetic factors of non-insulin dependent diabetes mellitus, together with the insulin resistance in peripheral tissues and the impairment of glucoseinduced insulin secretion from pancreatic beta cells. Recently, the therapeutic agents to inhibit the alpha-glucosidase of small intestine have been used for the treatment of NIDDM patients $(2,3$, $4,5,7,9,12,13)$. However, a few studies have been conducted concerning the comparison of alpha-glucosyldisaccharide digestive/absorptive capacity in normal and diabetic mice. On the other hand, in vivo studies related to the alphaglucosyldisaccharide digestive/absorptive capacity have rarely been performed in normal and diabetic mice. Therefore, we examined the alphaglucosyldisaccharide digestive/absorptive capacity using various disaccharides in both normal and diabetic mice, in vivo.

Materials. Maltose, sucrose and lactose were purchased from Wako Pure Chemical Industries Co. Ltd. (Osaka, Japan).

Correspondence to: Dr. T. Miura at the above address.

Tel: +81-593-83-8991; Fax: +81-593-83-9666
Animals. Adult male ddY mice (SLC, Shizuoka, Japan) weighing 22-25 g and KK-Ay mice (Clea, Tokyo, Japan) weighing 42-48 g were used. The mice were housed in an air-conditioned room at $22 \pm 2^{\circ} \mathrm{C}$ with a 12 hours light and 12 hours dark cycle. The animals were kept in the experimental animal room for 7 days with free access to food and water. For the determination of blood glucose levels, blood samples were withdrawn from the cavernous sinus with a capillary. Three to seven animals were used for each group.

Oral disaccharide tolerance test. After overnight $(20 \mathrm{~h})$ fasting, the mice were orally given sugar (maltose, sucrose, or lactose, $2 \mathrm{~g} / \mathrm{kg}$ body weight) solution. Blood samples were collected before the administration of sugar, and $0.5,1$ and $2 \mathrm{~h}$ later. Disaccharase activity. After overnight $(20 \mathrm{~h})$ fasting, maltose, sucrose or lactose $(100 \mathrm{mM}, 0.5 \mathrm{~mL})$ solution was injected into a loop of small intestine. After $0.5 \mathrm{~h}$, the inside of small intestine was washed by $5 \mathrm{~mL}$ of saline solution, and disaccharide content was determined for the evaluation of alpha-glucosyldisaccharide digestive/absorptive capacity, as described below.

Determination of blood ghucose, insulin and disaccharides in small intestine. Blood glucose levels in mice were determined by glucose oxidase 
method (11) and insulin was measured by a double-antibody immunoassay (1). The maltose, sucrose, and lactose content in small intestine was measured by means of the anthrone- $\mathrm{H}_{2} \mathrm{SO}_{4}$ method (6). All the data were expressed as mean \pm S.E.M. and Student's $t$ test was used for the statistical analysis. The values were considered to be significantly different when the $P$ value was less than 0.05 .

Blood glucose and plasma insulin level. The mean levels of blood glucose and insulin are shown in Table 1. The blood glucose and plasma insulin levels of KK-Ay mice are significantly higher than those of normal mice.

Oral disaccharide tolerance test. The mean blood glucose levels of ddY or KK-Ay mice at various time intervals after oral administration of maltose, sucrose or lactose are shown in Fig. 1 (ddY mice) and Fig. 2 (KK-Ay mice). In normal mice, the blood glucose in maltose tolerance is higher than that in sucrose or lactose. In KK-Ay mice, the blood glucose in sucrose is higher than that of lactose.

The blood glucose of normal mice in sucrose tolerance is higher than that of KK-Ay mice (Fig. 3).

Alpha-glucosyldisaccharides Digestive/Absorptive Capacity. The maltose digestive/absorptive capacity 30 min after the oral administration of maltose is shown in Fig. 4. The values were compared to those found in normal mice group. Maltose digestive/absorptive capacity of KK-Ay mice was higher than that of normal mice $(P<$ $0.05)$. The sucrose digestive/absorptive capacity 30 min after the oral administration of sucrose are shown in Fig. 4. Sucrose digestive/absorptive capacity of KK-Ay mice was increased when compared with that of normal mice $(P<0.05)$. On the other hand, no effect on lactose digestive/ absorptive capacity is shown in both normal and KK-Ay mice (Fig. 4).

The present study clearly shows that the alpha-

Table 1 Body Weight, Blood Glucose and Plasma Insulin Level

\begin{tabular}{cccc}
\hline & Body weight $(\mathrm{g})$ & Blood glucose $(\mathrm{mM} / \mathrm{L})$ & Plasma insulin $(\mu \mathrm{U} / \mathrm{mL})$ \\
\hline Normal mice & $24.0 \pm 0.5$ & $9.1=0.6$ & $34 \pm 6$ \\
\hline KK-Ay mice & $44.6 \pm 0.8^{* * *}$ & $29.2=1.1^{* * *}$ & $254 \pm 32^{* *}$ \\
\hline
\end{tabular}

Blood samples were taken at 11:00 am. Each value represents the mean \pm S.E.M. from 5 mice. Significantly different from normal mice, ${ }^{* *} P<0.01,{ }^{* * *} P<0.001$.

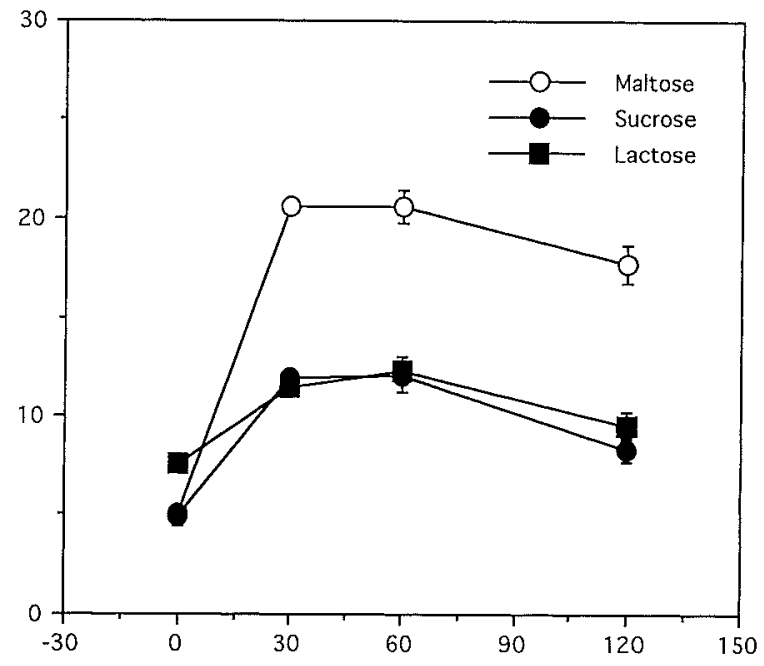

Fig. 1 Disaccharide Tolerance Test in Normal Mice.

Each value represents the mean \pm S.E. from 3-4 mice.

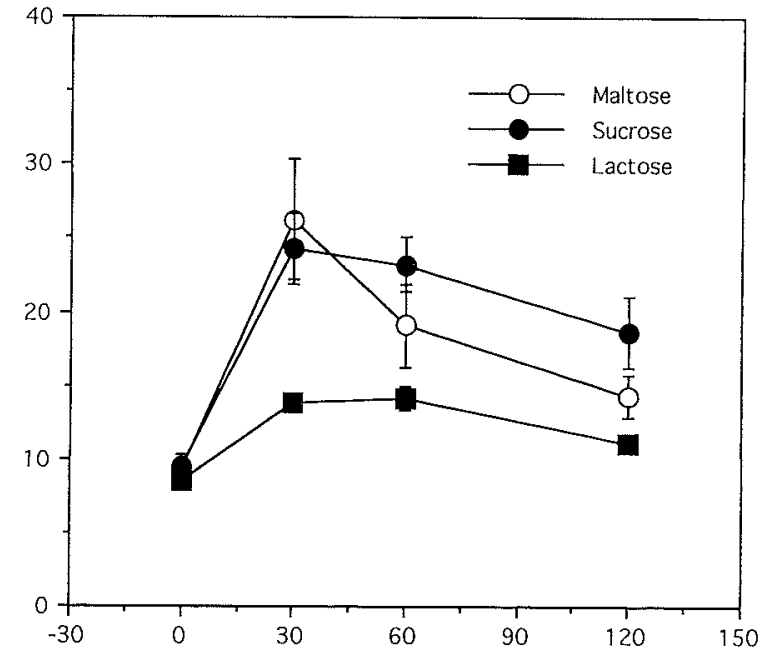

Fig. 2 Disaccharide Tolerance Test in KK-Ay Mice.

Each value represents the mean \pm S.E.M. from 3 mice. 


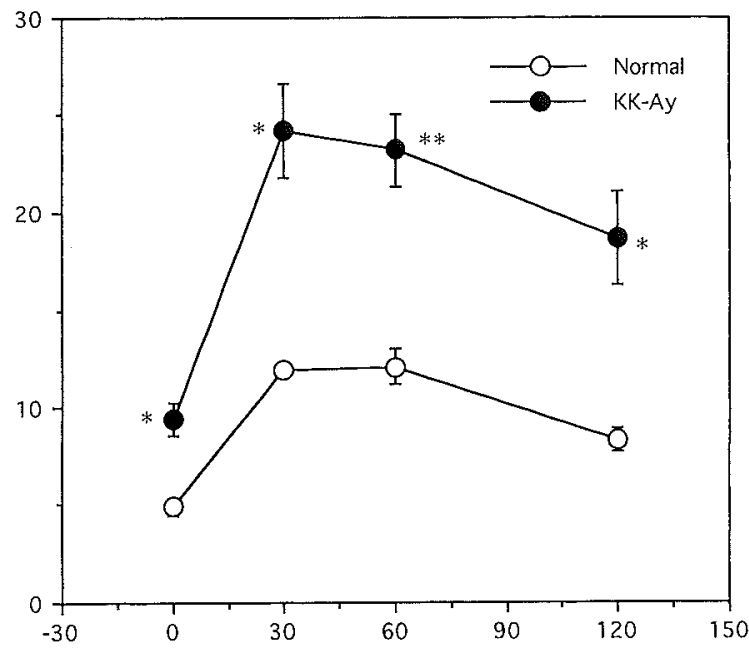

Fig. 3 Sucrose Tolerance Test in Normal and KKAy Mice

Each value represents the mean \pm S.E.M. from 3 mice. Significantly different from corresponding normal mice, ${ }^{*} P<0.05,{ }^{*} * P<0.01$.

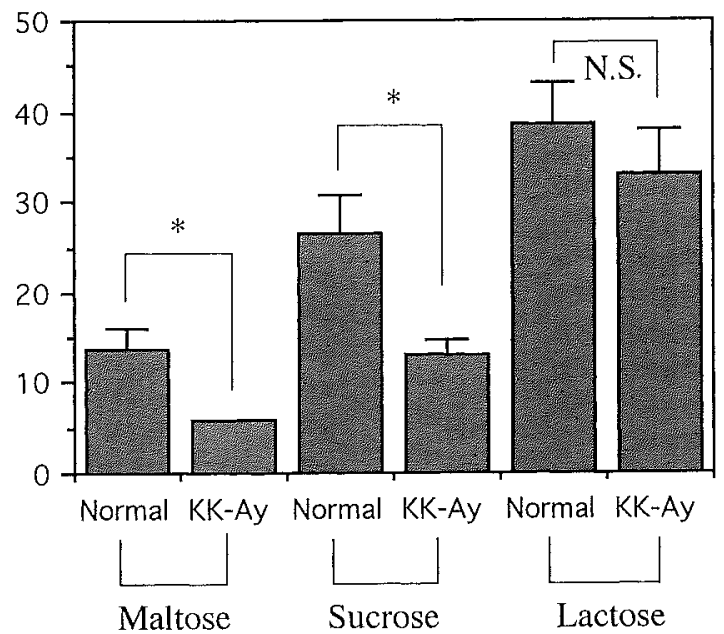

Fig. 4 Disaccharide Digestive/Absorptive Capacity in Normal and KK-Ay Mice.

Each value represents the mean \pm S.E.M. from 3-4 mice. Significantly different from corresponding normal mice, ${ }^{*} P<0.05, \mathrm{~N}$. S.; not significant.

glucosyldisaccharides digestive/absorptive capacity is increased in KK-Ay mice. We examined time-course $(0,30,60,120 \mathrm{~min})$ of blood glucose levels after the administration of maltose, sucrose or lactose, and found that they exhibited hyperglycemia at $30 \mathrm{~min}$ and thereafter. When calcu- lated the disaccharase activity in hyperglycemic KK-Ay mice, Maltase and sucrase activities of small intestine were significantly higher than those of normal mice. Hopfer (8). have reported that glucose absorption in experimental diabetic rats was twice as high as that in normal rat, and these findings indicate that the relative increase of glucose absorption was due to activation of $\mathrm{Na}^{+}-$ glucose transporter by changing the $\mathrm{Na}$ permeability. In addition, Madara et. al. (10) have reported that sucrase-isomaltase activity in experimental diabetic rats was significantly elevated when compared with normal rats. Our findings of the increment of sucrose and maltose digestive/ absorptive capacity in KK-Ay mice could also be related with the increment of $\mathrm{Na}^{+}$-glucose transporter activity. However, no significant change in lactose digestive/absorptive capacity was observed. The oligosaccharidases have been known to be composed of two classes; the betagalactosidases such as lactase (hydrolyse lactose to glucose and galactose) and the alphaglucosidases such as maltase, isomaltase, glucoamylase and sucrase. It is suggested in the present study that the increase of alphaglucosyldisaccharide digestive/absorptive capacity in KK-Ay mice is selective to the alphaglucosidases. This report will provide useful information for future studies on the treatment of NIDDM.

Received 7 September 1998; and accepted 10 October 1998.

\section{References}

1. Bailei C. J., Ahmed-Sorour H. (1980) Role of ovarian hormones in the long-term control of glucose hemeostasis. Diabetologia, 19, 475-477.

2. Braun C., Brayer G. D., and Withers S. G. (1995) Mechanism-based inhibition of yeast alpha-glucosidase and human pancreatic alpha-amylase by a new class of inhibitors. J. Biol. Chem., 270, 26778-26781.

3. Caspary W. F., and Graf S. (1979) Inhibition of human intestinal alpha-glucoside hydrolase by a new complex oligosaccharide. Res. Exp. Med, 175, 1-6.

4. Goda T., Yamada K., Hosaya N., and Moriuchi S. (1981) Effects of alpha-glucosidase inhibitor BAY g 5421 on rat intestinal disaccharidases. Food and Nutrition, 34, 139-143.

5. Hagel J., Ruppin H., Pichl J., Feuerbach W., and Bloom S. (1985) Alpha-glucosidase inhibitor acarbose: fate and effects in man. Gastroenterology, 88, 1410.

6. Hassid W. Z., and ABRaham S., Anthrone- $\mathrm{H}_{2} \mathrm{SO}_{4}$ method. Methods Enzymol., 3, 34 (1957).

7. Ho R. S., and ARANDA C. G. (1983) Influence of acarbose on hyperglycemia induced by various carbohydrates in rats and oral starch tolerance in monkeys. Arch. Intern. 
Pharmcodynamics, 261, 147-156.

8. Hopfer U. (1975) Diabetes mellitus: Changes in the transport properties of isolated intestinal microvillus membranes. Proc. Natl. Acad. Sci. USA, 72, 2027-2031.

9. Jenkins D. J. A., Taylor R. H., Goff D. V., Fielden H., and Misievicz J. J. (1981) Scope and specificity of acarbose in slowing carbohydrate absorption in man. Diabetes, 30, 951-954.

10. Madara J. L., Wolf J. L., and Trier J. S. (1982) Structural features of the rat small intestinal microvillus membrane in acute experimental diabetes. Digest. Diseas. and Sci., 27, 801-806.

11. MARKS V., and LLOYD K., Preservation of blood glucose analysis by glucose oxidase. Clin. Chim. Acta, 8, 326 (1963).

12. Radziuk J., Kemmer F., Morishima T., Berchtold P., and Vranic M. (1984) The effects of an alpha-glucoside hydrolase inhibitor on glycemia and absorption of sucrose in man determined using a tracer method. Diabetes, 33, 207-213.

13. Taylor R. H., Jenkins D. J. A, Barker H. M., Fielden H., and Goff D. V. (1982) Effect of acarbose on the 24-hour blood glucose profile and pattern of carbohydrate absorption. Diabetes Care, 5, 92-96.

14. William-Olsson T. (1985) Alpha-glucosidase inhibition in obesity. Acta Medica Scandinavia, 706 (Suppl.), 1-39. 